\title{
Analysis of the Use of Electronic Banking and e-Payments from the Point of View of a Client
}

\author{
Witold Chmielarz \\ University of Warsaw, Faculty of Management, \\ in Warsaw \\ ul. Szturmowa 1/3, 02-678 Warsaw, Poland \\ Email: witold@chmielarz.eu
}

\author{
Marek Zborowski \\ University of Warsaw, Faculty of Management, \\ in Warsaw \\ ul. Szturmowa 1/3, 02-678 Warsaw, Poland \\ Email: mzborowski@wz.uw.edu.pl
}

\begin{abstract}
The main aim of this article is to analyse the collected opinions on the use of electronic banking tools by individual clients in Poland, at the end of 2016. The research has been carried out using a CAWI method. The survey questionnaire, which was verified by finance experts, was made available to respondents on the servers of the Faculty of Management at the University of Warsaw. The following article structure has been adopted: after a brief introduction, the authors presented the assumptions of the conducted research and the research method, and subsequently the authors have carried out an analysis and discussion of the obtained findings and conclusions, which may be seen as supplementary in relation to previous studies conducted in the summer of 2016.
\end{abstract}

\section{INTRODUCTION}

$\mathbf{E}$ LECTRONIC banking is an economic sector which is developing in the most consistent and sustainable way. In relation to the third quarter of 2015, in the same time in 2016 the number of individual clients with potential access to account increased by $21.71 \%$ (which amounted to $4.94 \%$ more than in corresponding period in 2014/2015) reaching over 33.009 million users; the number of active individual clients in the same period increased by over $5.44 \%$ [13]. Thus, undoubtedly, due to mobile banking phenomenon, this is the fastest and simultaneously, the most spectacularly developing banking sector. The growth in the number of clients with potential internet access to account is accompanied with the continuous increase in the number of active clients (at least one banking operation a month); nevertheless, the share still fluctuates around up to $55 \%$. From year to year, the population of new users taking advantage of the opportunities created by the Internet to handle banking transactions is growing. Last year we could observe a continuous growth in the number of active individual clients from 14.468 million people to 15.300 million [5]. Thus, it is a significant, greatly diversified market, which may be seen as a wide area for research analyses.

The main aim of this article is to analyse the opinions on the use of electronic banking tools by individual clients in Poland at the end of 2016. IT banking system is a conglomerate of traditional and modern computer and Internet/network communication systems [1]. Among the modern systems, as indicated above, electronic banking enjoyed the greatest popularity. Ebanking is frequently divided according to the tools which are used to carry out transactions into particular areas such as: internet banking, mobile banking, payment cards systems, ATM and POS systems. The most popular kind of internet banking is here understood as the realization of business enterprises which uses the Internet to conduct banking operations. The realization consists in obtaining access to account by means of the Internet. The said access to the Internet may be obtained in two ways: by means of various devices/hardware and applications/software. The first is the access via a browser and a website. It may be carried out by means of traditional devices such as a laptop or a desktop computer or mobile devices such as a smartphone/tablet. The second one, which relates only to mobile devices, offers an additional possibility to perform banking functions using mobile applications [2].

\section{ASSUMPTIONS OF THE STUDY}

The discussions on the evaluation of the access to internet e-banking services are presented in an extensive body of the literature on the subject and based on considerable and valuable practical and research experience. However, there is no single evaluation approach which would determine a set of evaluation criteria which would be objectively regarded as the best and most suitable indicators from the point of view of individual clients [8], [9], [10], [11], [12], [14]. On the basis of the literature review one may conclude that ebanking websites/services may be analysed from the point of view of: their usefulness/usability (e.g.: site map, directory), interactivity (e.g.: availability and responsiveness), functionality (e.g. search engine, navigation and contents), visualisation (colour scheme, background, graphics, text, etc.), effectiveness (e.g.: cost of purchase, transport, the differences in prices in traditional and online shops), reliability and many others.

The available methods of websites evaluation do not fully cover the research problems associated with using the ebanking services [4]. They need to be accompanied by further studies which would complement the findings obtained additional studies. And it is difficult to compare with comprehensive survey surveys in this field included eg. in [6], [7]. The prototype of the survey was created in a traditional form and it was tested on a selected group of professionals, specialists in the area of finance and banking, and following the verification and modification of the questionnaire, the authors created an electronic version of the survey and made 
it available online to be completed by respondents. In the fact it was pilot study for more specified research of the chances for using of using m-banking in Poland tailored to the level of the user group. In December 2016, the authors carried out a study with the application of a CAWI (Computer Associated Web Interview) method examining the opinions of 193 respondents presenting their views on the use various manifestations of electronic banking, and the research may be seen as supplementary in relation to previously conducted studies. The sample was a case of purposeful sampling — the participants of the study were students of post-graduate studies at the Faculty of Management at the University of Warsaw and Vistula University in Warsaw, in the age of 19-25, in randomly selected lecture groups. On the one hand, the study included only one, specific age group. On the other, this is a group consisting of the most active users of modern technologies and - in this case - directly connected with the sector of finance (employees of banks, insurance agencies, accounting offices, etc.), who may be regarded as specialists in the field. Among the respondents there were $79.79 \%$ of women and $20.21 \%$ of men. This time, the greatest share of respondents $(29.53 \%)$ came from rural areas; the second place $(21,24 \%)$ was taken by people from towns below 50,000 residents $(23.83 \%)$; the third place from cities with over 500,000 inhabitants, mainly from Warsaw and surrounding areas. The remaining part, one fourth came from towns with 50,000-500,000 residents. The majority of the sample were people holding a BachelorâĂŹs degree, about $5 \%$ declared having secondary education, $72.02 \%$ were students, and $27.98 \%$ were working students.

\section{ANALYSIS AND DISCUSSION OF THE FINDINGS}

In the study the authors conducted a survey consisting of a few main parts: the evaluation of the knowledge concerning electronic banking services; evaluation of the electronic payments capacity; specification: social and demographic characteristics of the sample.

Among the 193 respondents who correctly completed the survey, only one person did not use electronic banking tools (taking the form of e.g. websites - internet banking, mobile applications of banks, ATMs, payment cards, contactless transactions, mobile payments, POS payments or money transfers). It was established that the respondents most frequently use access channels such as a combination of a laptop and a desktop computer (using websites) - $33.47 \%$ of the responses, ATMs - $27.02 \%$ and a combination of a smartphone and a tablet (using websites and mobile applications) - 22.18\%. The remaining combinations of access tend to be more and more marginalized. Clients of electronic banking most frequently use the standard services such as checking the account balance and history of transactions in the account $(42.96 \%)$ as well as making transfers $(42.26 \%)$. The latter is frequently connected with ma-king e-payment transactions. The remaining services are most frequently used by fewer than $15 \%$ of clients, out of which the greatest share (over 10\%) indicated toppingup mobile phones. In this particular age group there are few operations which are usually regarded as most commonly applied in e-banking such as opening fixed-term deposits $(2.31 \%)$ and establishing standing orders $(1.15 \%)$. Submitting online applications for these products is a very rare phenomenon $(0.69 \%)$. Over $16.58 \%$ of respondents have a few payment cards, and $81.87 \%$ one payment card. Only $1.55 \%$ respondents do not use any payment card. Interestingly, $6.62 \%$ of the respondents do not know what type of card they own. However, almost all survey participants $(99.48 \%)$ know whether their card has a proximity functionality. And thus $86.53 \%$ of the respondents own only proximity cards, $4.66 \%$ state that most of their cards are proximity cards, and only $8.29 \%$ do not own such a card. Out of the share of the sample holding proximity cards, an overwhelming majority $84.46 \%$ use them whenever they have such a possibility, and $4.66 \%$ only in selected, safe and reliable points of sales. The same group does not use such payments cards because they are concerned about the security of their transaction, and $6.22 \%$ of the sample do not own a contactless card at all. Attention should be given to a $2.24 \%$ discrepancy in plus between the holders of proximity cards, and their use (according to the respondentsâĂŹ claim there are more people who do not own proximity cards than those who use them). ATMs are used by the respondents in a traditional way mainly to withdraw cash $(46.44 \%)$ and to check the account balance $(23.59 \%)$, and $41.97 \%$ do not use them at all. Unfortunately, as many as $22.80 \%$ do not know if their smartphone offers a mobile payment options, and in consequence, they do not use them for such purposes. Few clients have used multimedia kiosks $-2.08 \%$ in total, to contact the banks and to withdraw cash. The remaining $97.93 \%$ of respondents have never used the multimedia kiosks.

Nevertheless, the respondents claim $(76,17 \%)$ that they have confidence in the various electronic banking tools. The remaining $3 \%$ either have no opinion on the subject or they are not convinced of the usefulness or reliability of these tools. Even ten years ago the problem of the lack of confidence in electronic banking was an obstacle discouraging over $35 \%$ of clients from using it. Despite the high level of trust in electronic banking, $48.72 \%$ of the respondents, if they use a different Internet access/network than their own Internet connection, then usually $-48.72 \%$ of the share use it at home, and $27.84 \%$ at the university. Using the Internet at work is less popular $(14.65 \%)$, and the least popular option $(8.79 \%)$ is using the Internet access in restaurants or at the airports. Generally, the issue of security is still important for users of e-banking. The greatest number $(43.53 \%)$ use a password to access the website and a text message with one-time password $(38.84 \%)$. It is important to note that the so-called "scratch card" (12.95\%) and a token $(4.13 \%)$ are losing its popularity. The "scratch card" owed its popularity to the fact that this is one of the cheapest forms of ensuring transaction security; however, at present it is being replaced with one-time SMS passwords. A token, by contrast has always been regarded as one of the most effective solutions guaranteeing transaction security. The above described aspect gains in importance since many users state that they have experienced situations 
which posed a threat to the safe use of e-banking tools. The greatest share of the respondents $(45.68 \%)$, which is also indicated in the analyses carried out by the authors in a [3], have encountered problems associated with hardware failures or software errors in websites. Half of the previous share $(24.07 \%)$ experienced problems related to the lack of sufficient knowledge with regard to using hardware. $14.20 \%$ of respondents recall receiving email messages containing requests to disclose the login or password they use to access e-banking services. The second part of the questionnaire was devoted to the respondentsâĂŹ use of e-payments. The survey findings show that the banking services which were most frequently used by the clients were on-line payments in the Internet $(22.06 \%)$ and ATM cash withdrawals (17.36\%). Other services which enjoy considerable popularity are the purchases of tickets (train, municipal transport fares) $-15.27 \%$; slightly less popular are card payments in a shop (POS) $-14.36 \%$. The high position in the ranking $(10.84 \%)$ was taken by paying bills and invoices as well as purchasing tickets for cultural or sporting events $(9.79 \%)$. In this group of users, other services, such as: topping-up mobile phones $(6.01 \%)$, purchase of digital content $(2.35 \%)$, e-wallet used for payments and settlements $(1.04 \%)$ and parking fees $(0.78 \%)$ are less popular. Among the respondents, $65.28 \%$ of individuals owning a smartphone or a tablet made a payment via a mobile device using a browser (website) or a mobile application at least once. The remaining share of $34.72 \%$ stated that they are ready and willing to do it in the nearest future. Among the respondents, the factors contributing to the popularity of using mobile devices were mainly $(56.78 \%)$ convenience, perceived savings and simply curiosity $(22.34 \%)$. The abovementioned curiosity with regard to the differences between using the services of Internet banks via mobile devices (smartphone/tablet) and traditional devices (laptop/desktop computer) or the differences between handling transactions in the case of mobile banking application and browser-based tools contributes to the increase in the number of transactions and the development of the mobile banking sector. Other relatively significant factors were attractiveness in financial terms (10.99\%) and fashion $(6.59 \%)$. In the usersâĂŹ view, the bankâĂŹs marketing campaign was the aspect which affected them the least $(3.30 \%)$. The subsequent questions included in the survey concerned the usersâĂŹ opinions on the payment technologies, which are not widely used at present, but believed to become very popular in the future. The clients were also asked about their expectations and predictions concerning the future development trends. The first query concerned the clientsâĂŹ approach towards the Blik system. It is a mobile payment system which enables ma-king payments both in the Internet and retail outlets (product and service POS), ATM cash withdrawals and money transfers between smartphone users. A prerequisite for its use is owning a smartphone running an e-banking mobile application which is compatible with the systems. $36.54 \%$ share of the respondents agreed with the statement that this method of payment will probably gain in popularity among young smartphone users and indicated that this method is similar to a payment with a proximity card $(25.59 \%)$. The third place with regard to clientsâĂŹ opinions (19.93\%) was taken by the convenience of the transaction. Nearly $7 \%$ of the respondents claimed, however, that this new technology is not sufficiently secure, and nearly about $3 \%$ - were of the opinion that it is too complicated for an average user. Simultaneously, almost $10 \%$ had no opinion on the subject. The transfers between Blik users was the most recently introduced service on the market. In the case of this service, there is no need to enter the account number containing 26 digits, the user may use the telephone number of the recipient of the transfer. The condition for making an instant transfer is using the banking system which is compatible with the system and a prior registration of the phone number. If the userâĂŹs number is not registered yet, he/she receives a text message (SMS) with an instruction on how to collect the money which is transferred according to KIR (National Clearing House) session. $43.41 \%$ of respondents believe that in the future such transfers will be a generally applied, fast method of settlement of oneâǍŹs financial obligations. An almost equally large group of clients $(41.95 \%)$ believe that, even though they are not using this method of payment, these solutions will become popular soon. Almost 5\% of the sample claim that such transfers are not secure, they do not seem reliable and that they will not be adopted, and nearly $10 \%$ admit that they do not know such solutions at all. Another kind of payment, micro-transfers (where the maximum value of a single trans-action is PLN 50) via Facebook to a friendâĂŹs account, represents yet another manifestation of modern technology applications in banking services. This functionality was first provided by AliorSync, a worldwide pioneer in this regard, and it is made possible thanks to an account being linked to the userâĂŹs Facebook account. However, this requires some initial steps to be taken: first, the user needs to log in to AliorSync electronic banking, create a special account and install a dedicated application on his/her smartphone. The recipients of the money transfer must be on the list of our Facebook friends, and the autoidentification procedure is carried out via the code sent by SMS. More than half $(54.21 \%)$ of the respondents have never heard of this method of payment - perhaps, it has not been widely promoted or used so far. Almost $22 \%$ of the sample state that they have never used it; still, they believe that it may be commonly applied in the future due to the general popularity of Facebook and its influence on its users. However, as many as $23.36 \%$ of the respondents are of the opinion that this may be very dangerous, does not inspire confidence and probably will not be accepted in everyday life. A very similar distribution of opinions may be observed in the case of the views concerning money transfers made to an email address. In order to make such a transfer, one simply needs to know the email address of the recipient. Due to the simplicity of the procedure, most banks have introduced a one-time transfer limit for security purposes. However, this is not a very popular method $-52.66 \%$ of the survey participants stated that they have never heard about this solution, and as many as $26.57 \%$ believe that this method is not secure and it raises some 
concerns. Only the remaining over $20 \%$ sees its great potential for future development.

\section{CONCLUSIONS}

The presented analysis points to considerable diversity in the opinions of individual clients on the issue of using e-banking systems, associated with the selection and use of websites for banking operations which would meet their everyday needs in this regard. In relation to previously conducted research [3], the present study indicates also the changes with regard to clientsâĂŹ awareness and activity, which have taken place in recent years. An individual client of e-banking services has changed from the user of its basic functions into a conscious customer being aware of the advantages and disadvantages of this modern form of communication and electronic payment functionalities associated with it.

The recapitulation of the authorsâĂŹ considerations and research findings leads to the following conclusions:

- in recent years, the most significant phenomenon which occurred in the e-banking market is mobile access to banking services. It can take two forms: access via banking websites and via banking applications running on mobile devices such as smartphones and tablets. At present, the access via mobile applications is estimated at over $22 \%$,

- increase in banking fees announced and expected to be implemented in 2017 may bring about changes with regard to owning and using payments cards. In 2016, we were witnesses to increases in fees for account maintenance and ATM cash withdrawals e.g.: ING, Pekao, $\mathrm{BPH}$. Currently, other banks are planning to introduce the changes in the charges: Bank Handlowy (account maintenance, using a debit card, money transfers and cash withdrawals from ATMs), Citi Bank (using cards, charges for selected money transfers, withdrawals from the ATM of another bank, rise in account maintenance charges in the case of selected accounts (e.g. City Priority)). A complex and confusing way of increasing charges for banking services may discourage users to own one or more than one payment cards. At present, nearly 17\% of respondents own more than one payment card,

- among the payment cards owned by the respondents, debit cards constitute the majority of the share $(71.16 \%)$, the campaign promoting credit cards have not changed the

- usersâĂŹ habit of many years consisting in using the debit cards which are generally regarded as safer; nevertheless, over $86 \%$ of survey participants own proximity cards,

- a similar traditional approach may be observed in the case of using ATMs mainly for cash withdrawals,

- the security of using e-banking services and e-payments is still very important from the point of view of users, but to a smaller extent than a few years ago. The most frequently used security method (nearly $44 \%$ of the share) are passwords enabling the users to log into the system and one-time SMS passwords entered to confirm the transaction (nearly 39\%),

- the distribution of the kinds of transactions being conducted is almost uniform. Most frequently, the survey participants make payments using Internet banking (over $22 \%$ ) or ATMs (more than 17\%). Subsequently, they buy public transport tickets and pay with a card in a traditional shop,

- more than $65 \%$ of the respondents have made at least one payments via a mobile device, and they were usually influenced by factors such as convenience and costeffectiveness (nearly 57\%),

- the users are still cautious with regard to new and innovative systems. $36.54 \%$ of the survey participants agreed that Blik payments is a technology which has great potential for development and in the nearest future it may be used more and more commonly; however, they had certain reservations related to ensuring the security of the system. Similar results have been obtained in the case of micropayments which may be realised via Facebook or transfers made to an email address. In addition, a large group of people, that is $40-50 \%$ in each of the mentioned cases, claim that they have not heard about such methods.

The diversification and dynamics of the evaluations seem to confirm the thesis related to the necessity to conduct ongoing analyses of this sector, with particular attention being paid to the usefulness and cost-effectiveness of services as well as the tendencies concerning the design and usability of websites from the clientsâÁŹ point of view. This also justifies the need to further investigate the development trends in order to construct a multi-dimensional, multi-criteria, hierarchical and multi-aspect system for the evaluation of e-banking, which in addition to the presently considered aspects would incorporate detailed criteria such as e.g. customer profile. This particular area may be the object of research in the future; however, at present it appears that electronic banking, which combines various tools, technics and methods used in its operations, constitutes the complex structure in itself, and does not necessitate the studies of such a vast scope. One may notice a new trend consisting in the fact that the position of mobile access is increasingly prominent, and browser-based tools and mobile applications running on mobile devices seem to take over the part of the market traditionally served by access to account using personal and desktop computers. It is also increasingly evident that the development irreversibly changes clientsâĂŹ requirements, assumptions and habits concerning operations conducted in the banking sector, and conversely - it also necessitates faster changes of the medium, which would take into account the usersâÁ ź expectations and demands.

\section{REFERENCES}

[1] Chmielarz W., Systemy elektronicznej bankowości, Difin, 2005

[2] Chmielarz W., Łuczak K., Mobile Payment Systems in Poland Analysis of Customer Preferences, in: Transformations in Business \& Economics, Vol. 15, no. 2a (38A), 2016, pp. 523-538. 
[3] Chmielarz W., Zborowski M., Conversion Method in Comparative Analysis of e-Banking Services in Poland in: Chapter 4 entitled: Information Systems and Services in: Perspectives in Business Informatics Research eds. A. Kobylinski, A. Sobczak in: Lecture Notes in Business Information Processing no. 158, Springer Verlag, Berlin, Heidelberg, 2013, pp. 227-240, DOI: 10.1007/978-3-319-45321-7.

[4] Chmielarz W., Zborowski M., Comparative analysis of e-banking services of the most popular banking websites in Poland in 2016, an article sent for publication in X-th SIGSAND/PLAIS Eurosymposium'2017, conference materials, 2017.

[5] https://zbp.pl/public/repozytorium/wydarzenia/images/styczen_2017/ konferencja_praso, 2016., accessed February 2017.

[6] http://www.marketest.co.uk/market-researchquestionnaire/91/banking_services, accessed June 2017.

[7] https://www.scribd.com/doc/20110339/Questionnaire-for-onlinebanking-survey, accessed June, 2017.

[8] Hui-Min Z., The study on evaluation of e-banking websites from the view point of customers, Computer Design and Applications (ICCDA), 2010, IEEE, http://www.ieee.org/conferences_events/conferences/conferencedetails/ index.html?Conf accessed March 2017, DOI: 10.1109/ICCDA.2010.5541414.

[9] Marete1 J. M., Gommans H. P., Gongera E. G., An Evaluation of E-Banking Services on Customer Satisfaction: Case of National
Bank of Kenya, European Journal of Business and Management, European Journal of Business and Management, 2014, pp. 228-238, at: http://www.iiste.org/Journals/index.php/EJBM/article/view/14472; accessed March 2017,

[10] Mera M. B., Gonzales A. C., Lopez O.R., A new Web assessment index: Spanish universities analysis, Internet Research: Electronic Application and Policy, 11(3), 2001, DOI: 10.1108/10662240110396469.

[11] Migdadi Y. K., Quantitative Evaluation of the Internet Banking Service Encounter's Quality: Comparative Study between Jordan and the UK Retail Banks, Journal of Internet Banking and Commerce, 2 (13), 2008.

[12] Miranda, F. J., Cortes R., Barriuso C., Quantitative Evaluation of e-Banking Web Sites: an Empirical Study of Spanish Banks, The Electronic Journal Information Systems Evaluation, 2(9), (2006), at: http://www.eiise.com, accessed March 2015, DOI: 10.4236/jssm.2010.31014.

[13] NETB@nk, NETB@nk Raport Bankowość internetowa i płatności bezgotówkowe. Podsumowanie III kwartału 2016 r., Związek Banków Polskich (The Polish Bank Association).

[14] Soufi B., Survey and Expert Evaluation for e-Banking. In: Yamamoto S. (ed.) Human Interface and the Management of Information. Information and Interaction Design. HIMI 2013. Lecture Notes in Computer Science, vol. 8016. Springer, Berlin, Heidelberg, 2013, pp. 375-382; accessed March 2017, DOI: 10.1007/978-3-642-39209-2_43. 